Images of

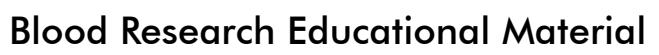

BLOOD RESEARCH

Volume $55 \cdot$ Number $2 \cdot$ June 2020

https://doi.org/10.5045/br.2020.2020059

\title{
Lineage switch from B lymphoblastic leukemia with KMT2A-rearranged to mixed-phenotype acute leukemia under daratumumab
}

Javier Marco-Ayala, Ana Isabel Vicente, Esperanza Such, Irene Luna, Rafael Andreu, Amparo Sempere, Samuel Romero, María Leonor Senent Peris

Department of Hematology, La Fe University Hospital, Valencia, Spain

Received on March 29, 2020; Revised on April 3, 2020; Accepted on April 21, 2020

Correspondence to Javier Marco-Ayala, M.D., Department of Hematology, La Fe University Hospital, Avinguda de Fernando Abril Martorell, 106, Valencia 46026, Spain, E-mail: javi.marco.ayala@gmail.com

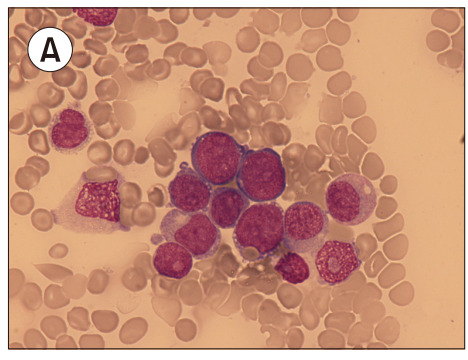

(C)

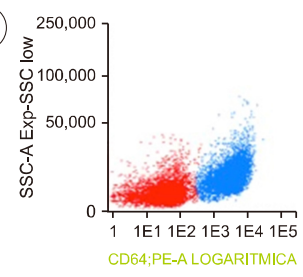

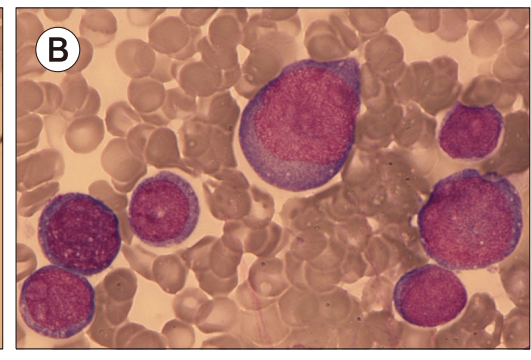

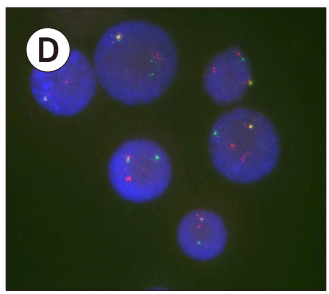

A 10-year-old girl presented with leukocytosis $\left(199 \times 10^{9} / \mathrm{L}\right)$, anemia $(9 \mathrm{~g} / \mathrm{dL})$, and thrombocytopenia $\left(34 \times 10^{9} / \mathrm{L}\right)$. After bone marrow (BM) study, she was diagnosed with B-lymphoblastic leukemia with $\mathrm{t}(4 ; 11)(\mathrm{q} 21 ; \mathrm{q} 23)$ and $K M T 2 A-A F F 1$ rearrangement. Following acute lymphoblastic leukemia therapy and early relapse, she participated in a clinical study with daratumumab (anti-CD38 monoclonal antibody).

BM re-evaluation after one treatment cycle showed that $40 \%$ of total nucleated cells (TNC) comprised medium blasts with irregular-shaped nucleus, scant basophilic cytoplasm, and similar immunophenotypic characteristics as the B-lymphoblasts during initial diagnosis; however, $56 \%$ of TNCs comprised large blasts with abundant cytoplasm and round nucleus. Flow cytometry showed these were similar to monoblasts and positive for CD64, CD4, CD15, and CD33 (A, B, May Grünwald-Giemsa stain, $\times 600$ and $\times 1,000$, respectively; C, monoblasts in blue, lymphoblasts in red). Fluorescence in situ hybridization confirmed $K M T 2 A$ rearrangement in both populations (D). She was diagnosed with mixed-phenotype acute leukemia with $\mathrm{t}(4 ; 11)(\mathrm{q} 21 ; \mathrm{q} 23)$.

Acute leukemia lineage switch is rare and has poor outcome. $K M T 2 A$ rearrangement is frequently involved because of its relationship with an immature hematopoietic precursor which can be transformed under certain circumstances. This is the first case involving daratumumab. Light microscopy is essential to detect lineage shift. 